\title{
Increased soil frost versus summer drought as drivers of plant biomass responses to reduced precipitation: results from a globally-coordinated field experiment
}

Shortened title: Plant biomass responses to soil frost and drought

Hugh A.L. Henry ${ }^{*}$, Mehdi Abedi², Concepción L. Alados ${ }^{3}$, Karen H. Beard ${ }^{4}$, Lauchlan H. Fraser $^{5}$, Anke Jentsch ${ }^{6}$, Juergen Kreyling ${ }^{8}$, Andrew Kulmatiski ${ }^{4}$, Eric G. Lamb ${ }^{9}$, Wei Sun ${ }^{10}$, Mathew R. Vankoughnett ${ }^{11}$, Susanna Venn ${ }^{12,13}$, Christiane Werner ${ }^{14}$, Ilka Beil ${ }^{8}$, Irmgard Blindow $^{8}$, Sven Dahlke ${ }^{8}$, Maren Dubbert ${ }^{14}$, Alexandra Effinger ${ }^{8}$, Heath W. Garris ${ }^{5}$, Maite Gartzia $^{3}$, Tobias Gebauer ${ }^{15}$, Mohammed A. S. Arfin Khan ${ }^{6,7}$, Andrey V. Malyshev ${ }^{8}$, Charles Nock $^{15}$, Janelle P. Paulson ${ }^{5}$, Yolanda Pueyo ${ }^{3}$, Holly J. Stover ${ }^{1}$ and Xuechen Yang ${ }^{10}$

${ }^{1}$ Department of Biology, University of Western Ontario, London, ON, Canada, ${ }^{2}$ Department of Range Management, Tarbiat Modares University, Iran (Islamic Republic of), ${ }^{3}$ Instituto Pirenaico de Ecología, (CSIC), Avda. Montañana 1005, Zaragoza 50059, Spain, ${ }^{4}$ Department of Wildland Resources and the Ecology Center, Utah State University, USA, ${ }^{5}$ Department of Natural Resource Sciences, Thompson Rivers University, Canada, ${ }^{6}$ Disturbance Ecology, BayCEER, University of Bayreuth, Germany, ${ }^{7}$ Department of Forestry and Environmental Science, Shahjalal University of Science and Technology, Bangladesh, ${ }^{8}$ Experimental Plant Ecology, Greifswald University, Germany, ${ }^{9}$ Department of Plant Sciences, University of Saskatchewan, 51 Campus Dr. Saskatoon, SK, Canada S7N 5A8, ${ }^{10}$ Institute of Grassland Science, Northeast Normal University, China, ${ }^{11}$ Department of Biological Sciences, University of WisconsinRichland, USA, ${ }^{12}$ Research School of Biology, Banks Building, Daley Rd, Australia National 
University, Acton, ACT, 2601, Australia, ${ }^{13}$ Research Centre for Applied Alpine Ecology, Department of Ecology, Environment and Evolution, La Trobe University, Bundoora, VIC, 3086, Australia, ${ }^{14}$ Ecosystem Physiology, University Freiburg, Germany, ${ }^{15}$ Geobotany, Faculty of Biology, University of Freiburg, Germany

*corresponding author - phone: 1-519-661-2111x81548, fax: 1-519-661-3935, email:

hhenry4@uwo.ca

Author contributions: HALH conceived of and designed the study and analysed the data; all authors performed research and wrote the paper 


\begin{abstract}
Reduced precipitation treatments often are used in field experiments to explore the effects of drought on plant productivity and species composition. However, in seasonally snow-covered regions reduced precipitation also reduces snow cover, which can increase soil frost depth, decrease minimum soil temperatures and increase soil freeze-thaw cycles. Therefore, in addition to the effects of reduced precipitation on plants via drought, freezing damage to overwintering plant tissues at or below the soil surface could further affect plant productivity and relative species abundances during the growing season. We examined the effects of both reduced rainfall (via rain-out shelters) and reduced snow cover (via snow removal) at 13 sites globally (primarily grasslands) within the framework of the International Drought Experiment, a coordinated distributed experiment. Plant cover was estimated at the species level and aboveground biomass was quantified at the functional group level. Among sites, we observed a negative correlation between the snow removal effect on minimum soil temperature and plant biomass production the next growing season. Three sites exhibited significant rain-out shelter effects on plant productivity, but there was no correlation among sites between the rain-out shelter effect on minimum soil moisture and plant biomass. There was no interaction between snow removal and rain-out shelters for plant biomass, although these two factors only exhibited significant effects simultaneously for a single site. Overall, our results reveal that reduced snowfall, when it decreases minimum soil temperatures, can be an important component of the total effect of reduced precipitation on plant productivity.
\end{abstract}

Keywords: climate, drought, International Drought Experiment, frost, productivity, rain, snow cover, winter 


\section{Introduction}

Drought is among the most influential plant stresses globally, and it is anticipated to increase in some regions over the next century as a result of climate change (Sheffield and Wood, 2008; Dai, 2011, 2013). Climate warming can contribute to drought by increasing evaporative demands/potential evapotranspiration rates, and at the regional level, periods of reduced precipitation can be a particularly strong driver of drought conditions (Trenberth et al., 2014). Numerous field experiments have been conducted at the plot level within sites to examine the effects of reduced precipitation on plant communities via the use of rain-out shelters (sensu (Svejcar et al., 1999) and (Yahdjian and Sala, 2002). Although severe drought inevitably decreases plant productivity (Breshears et al., 2005; Ciais et al., 2005; Allen et al., 2010), reduced precipitation per se typically has site-specific and at times apparently idiosyncratic results, due in part to differences in plant community composition, soil type and treatment intensity (Skinner et al., 2004; English et al., 2005; Carlyle et al., 2014). Rain-out shelter effects also can be highly contingent on the ambient weather conditions over the course of study (Kreyling et al., 2017).

A recent meta-analysis demonstrated that aboveground plant productivity is generally more sensitive to increases in precipitation than to reductions, with little variation in the effects of reductions across large-scale precipitation and temperature gradients (Wilcox et al., 2017). While meta-analyses can be useful for synthesizing information and identifying broad patterns across multiple sites, they are limited by often having to integrate data collected using different methods, and in cases where they rely primarily on published data they can be biased against the inclusion of null results (Hillebrand and Cardinale, 2010; Whittaker, 2010; Harrison, 2011). To address these concerns, it has been suggested that globally-coordinated distributed experiments 
should be organized to address major questions in ecology (Fraser et al., 2013). This approach has been successfully implemented to examine, for example, climate warming in the Arctic (ITEX; (Henry and Molau, 1997), the effects of nutrient enrichment and grazing (NutNet; (Borer et al., 2014) and plant diversity-productivity relationships (HerbDivNet; (Fraser et al., 2014). More recently, the International Drought Experiment (IDE) has been initiated to examine drought effects across a range of sites globally using rain-out shelters (Knapp et al., 2017).

In seasonally snow-covered regions, reduced precipitation also can reduce snow cover. The latter can lead to increased soil frost depth, decreased minimum soil temperatures and an increase in the frequency of soil freeze-thaw cycles, even when it is coupled with increases in mean annual air temperatures (Henry, 2008), resulting in the apparent paradox of colder soils in a warmer world (Groffman et al., 2001). Therefore, in addition to the effects of reduced precipitation on plant productivity via drought, reduced snow cover resulting from decreased winter precipitation can increase freezing damage to overwintering plant tissues at or below the soil surface (Tierney et al., 2001; Gaul et al., 2008; Comerford et al., 2013; Campbell et al., 2014), further affecting plant productivity and relative species abundances (Kreyling et al., 2012a; Vankoughnett and Henry, 2014). In addition to plant freezing damage, plants can respond to freezing indirectly via changes in soil microorganisms and nutrient availability (Henry, 2007; Blankinship and Hart, 2012), soil aggregates (Freppaz et al., 2008) or soil fauna (Templer et al., 2012). Decreased snow cover also can affect plant growth during the subsequent growing season by altering soil water dynamics (Iwata et al., 2010) and spring phenology (Dunne et al., 2003; Huelber et al., 2006; Wipf et al., 2006; Venn and Morgan, 2007; Natali et al., 2012). 
Although plant frost and drought stress typically occur in different seasons, plant stress tolerance can be modified by prior exposure to a different stress over the time scale of months (Kreyling et al., 2012b; Kreyling et al., 2012c; Kong and Henry, 2016), due to the phenomenon described as stress memory or cross acclimation (Walter et al., 2013). The latter may be explained by the accumulation of protective compounds or transcription factors that upregulate genes that confer stress tolerance (Bruce et al., 2007; Walter et al., 2013). Moreover, in the case of prior frost effects on drought stress, when frost damage reduces plant biomass it can result in decreased transpirational water losses during the subsequent growing season.

We examined the effects of both reduced rainfall (via rain-out shelters) and decreased snow cover (via snow removal) on plant cover and aboveground biomass at 13 sites globally within the framework of the International Drought Experiment, a coordinated distributed experiment (Knapp et al., 2017). Snow was removed opportunistically from the beginning until the middle of winter to increase soil freezing, and snow removal stopped before the end of winter to minimize its effects on spring melt water and spring phenology. Following snow melt, half of the snow removal and ambient snow plots were covered with rain-out shelters designed to reduce rain throughput at each location by an amount equivalent to a one-in-one hundred year drought, and the other half were left as ambient rain controls. Our primary goal was to assess, across a range of sites, the extent to which increased frost caused by reduced snow cover might be an important component of the effects of reduced precipitation on plant biomass compared to summer drought. We predicted that snow removal would decrease biomass to the greatest extent in the coldest sites. We also were interested in examining the extent to which the frost and drought effects might interact, with the prediction that prior exposure to frost would decrease the negative effects of drought on plant biomass. 


\section{Methods}

Study sites

Thirteen sites globally (from North America, Europe, Asia and Australia) participated in the experiment (Table 1, Fig. 1), and these were primarily characterized by grassland/old field vegetation, although a heathland site and the understory of a riparian forest site also were included. Mean January temperatures ranged from -22 to $2{ }^{\circ} \mathrm{C}$, and mean annual precipitation ranged from 200 to $1405 \mathrm{~mm}$ (Table 1). Mean annual snowfall ranged from 5 to $194 \mathrm{~cm}$. For each site, the treatments and data collection were conducted over a single year (2014-2015 for Bayreuth, ESW, Hardware Ranch, Kernen and Lac du Bois, 2015-2016 for Changling, Golestan, Hiddensee, Freiburg, Ordesa, Pineta and Richland, and 2016-2017 for Bogong).

\section{Snow removal and rain-out shelter treatments}

Within sites, a minimum of six $3 \mathrm{~m} \times 3 \mathrm{~m}$ plots were delineated (Bogong, Freiburg and Changling used eight plots, Bayreuth used 10 plots, and Hiddensee used 12 plots), with two $1 \mathrm{~m}$ $\times 1 \mathrm{~m}$ subplots within the center of each plot; the rain-out shelter and snow removal treatments were administered in a split-plot design with snow removal (subplots) nested in rain-out sheltering (whole plots; Figure 2). The $3 \mathrm{~m} \times 3 \mathrm{~m}$ plot size was determined based on the plot size requirements of the International Drought Experiment (Knapp et al., 2017). Within each plot, one sub-plot was assigned randomly to snow removal, and the other left as a control to experience ambient snow cover. To minimize disturbance to the soil and plant litter layer, plastic netting (with $1 \mathrm{~cm}$ gaps in the mesh) was placed over both the snow removal and ambient snow sub-plots before the first snowfall. In addition, soil temperature sensors were placed $2 \mathrm{~cm}$ below the soil surface in the center of each snow removal and snow control plot. To increase soil frost, 
snow was removed opportunistically (typically following major snowfall events) with shovels and brooms down to the level of the plastic mesh. However, snow was allowed to accumulate in the snow-removal sub-plots in late winter to minimize the treatment effects on growing season soil moisture and spring phenology. The Freiburg site received negligible snow cover and thus did not participate in the snow removal component, and the Bogong site also did not contribute snow removal data, despite snow being present at the latter.

After the final snow melt, rain-out shelters were installed over half of the plots at each site; each rainout shelter consisted of a metal or wooden frame with angled troughs made of transparent plastic to reduce each rainfall event passively by a fixed percentage (sensu (Yahdjian and Sala, 2002). The percent reduction of rain was calculated independently for each site (Table 1) to achieve a statistically extreme deviation in annual precipitation relative to long-term records (i.e. equivalent to that which has occurred $1 \%$ of the time historically based on annual precipitation amounts - either long-term climatological data or interpolated data - for the past 100 years for each site; Knapp et al., 2017). Therefore, although the percentage reduction varied among sites, the statistical extremity of drought was comparable across sites. Throughout the growing season, soil moisture from $0-15 \mathrm{~cm}$ depth was determined at regular intervals for the

plots at each site either using moisture sensors or gravimetrically. Neither the Bogong or Golestan sites collected soil moisture data, and nor were rainout shelters permitted at the latter site.

Plant cover and biomass

In the summer, percent aboveground cover was estimated separately for each species rooted within each snow removal and ambient snow sub-plot using a modified Daubenmire method (Daubenmire 1959, Bonham et al. 2004), in which cover is estimated to the nearest $1 \%$ 
for each species rooted within the plot. Percent cover also was estimated for woody overstory, litter, bare soil, animal diggings/disturbance, and rocks if present. Within-season sampling frequency was adjusted for individual sites based on the phenology of the component species to capture the maximum cover of each species. At the timing of peak biomass, rooted aboveground biomass was harvested from the plots and sorted by species and separated into the following six categories: 1. previous year's dead, and current year's: 2. bryophytes, 3. graminoids (grasses, sedges, rushes), 4. legumes, 5. non-leguminous forbs, 6. woody growth. The Lac du Bois (CA) site was only able to contribute total aboveground biomass data (i.e. not sorted by functional group), and the Golestan (IR) site could only contribute plant cover data. All biomass was dried at $60^{\circ} \mathrm{C}$ for a minimum of $48 \mathrm{~h}$ prior to weighing to the nearest $0.01 \mathrm{~g}$. For seven sites (Bayreuth DE), Changling (CN), ESW (CA), Hardware Ranch (US), Ordesa (ES), Pineta (ES) and Richland (US), standing root mass was measured at the timing of the aboveground biomass harvest from at least two $2 \mathrm{~cm}$ diameter by $15 \mathrm{~cm}$ deep soil cores collected from each subplot.

\section{Statistical analyses}

Too assess the treatment effects on soil temperature and soil moisture, the responses of minimum annual temperature, number of freeze-thaw cycles and minimum annual soil water content were analysed. Total aboveground biomass was analysed for the date from each site that featured the highest biomass values, and these analyses were followed by analyses of treatment effects on the total aboveground biomass for each functional group. For plant cover, the maximum growing season value for each species in each plot was first determined, then summed for each plot. The biomass data were $\log _{10}$-transformed, and the percent cover data were square root-transformed, in order to meet the assumption of normality for the subsequent statistical analyses. 
Dependent variable responses to the snow removal and rain-out shelter treatments, along with their interaction, were analysed in a nested fashion: first among the replicate plots within each site, then among sites. For within-site analyses, the responses were assessed using split-plot analysis of variance (ANOVA), with the understanding that these analyses might be limited by low statistical power (i.e. the focus of coordinated distributed experiments is on maximizing the number of replicate sites, whereas the workload at each site is minimized to encourage widespread participation). Therefore, marginally significant trends in the data (i.e. $\mathrm{P}<0.1$ ) were noted. For the among site analyses, two-way ANOVA with site included in the model as a random factor revealed no significant interactions between the snow removal and rain-out shelter effects for the plant response variables. Follow-up analyses were therefore performed on the snow removal and rain-out shelter effects separately. Specifically, the log response ratios of the biomass responses for each site were regressed against the treatment effects on minimum soil temperature, number of soil freeze-thaw cycles (i.e. transitions to below $0{ }^{\circ} \mathrm{C}$ then back again), minimum soil water content and the percentage of rain blocked by the rain-out shelters. All statistical analyses were performed using JMP ${ }^{\circledR} 13$ software (SAS Institute Inc., Cary, NC).

\section{Results}

\section{Treatment effects on soil temperature and soil moisture}

Snow removal decreased minimum soil temperature among sites $(\mathrm{P}<0.001)$, but there was an interaction between snow removal and site $(\mathrm{P}<0.001)$ resulting from some sites showing a strong effect, and others no effect (Table 2$)$. There also was an interaction $(\mathrm{P}=0.002)$ between snow removal and site for the number of soil freeze-thaw cycles, with some sites exhibiting an 
increase and others a decrease (Table 2). The rain-out shelters reduced minimum soil water content among sites $(\mathrm{P}=0.041$; Table 2$)$, and there was no significant effect of snow removal on post snow-melt soil water content $(\mathrm{P}=0.87)$.

\section{Plant biomass and cover responses}

Within sites, there were no interactions between snow removal and rain-out shelter effects for aboveground biomass or cover (therefore, the snow removal data displayed in the figures were pooled over the rainout shelter treatments, and vice versa). Snow removal reduced aboveground biomass for ESW $(\mathrm{P}=0.027)$ and Lac du Bois $(\mathrm{P}=0.020)$, and there was a marginally significant aboveground biomass reduction for Changling $(\mathrm{P}=0.0745$; Fig. 3a). These effects were driven by decreases in legumes (ESW; $\mathrm{P}=0.017$ ) and grasses (Changling; $\mathrm{P}$ $=0.020)$. Snow removal also reduced total percent cover for Changling $(P=0.020)$ and Golestan ( $(\mathrm{P}=0.007$; Fig. $3 \mathrm{~b})$, with the effects driven by decreases in grasses $(\mathrm{P}=0.02$ and $\mathrm{P}=$ 0.034, respectively). Rain-out shelters reduced aboveground biomass for Kernen $(P=0.007)$, Changling $(\mathrm{P}=0.002)$ and Freiburg $(\mathrm{P}=0.04$; Fig. 4a). These effects were driven by decreases in grasses (Kernen, $\mathrm{P}=0.004$; Changling, $\mathrm{P}=0.02$ ) and forbs (Freiburg, $\mathrm{P}=0.031$ ). Rain-out shelters also resulted in a moderately significant increase in aboveground biomass for Lac du Bois $(\mathrm{P}=0.08$; Fig. 4a). For total percent cover, there was a moderately significant increase under rain-out shelters for Lac du Bois $(\mathrm{P}=0.078$; Fig. $4 \mathrm{~b})$, driven by a significant increase in legumes $(\mathrm{P}=0.048)$. Rain-out shelters also resulted in a decrease in forb cover for ESW ( $\mathrm{P}=$ 0.013). Snow removal resulted in a $19 \%$ decrease in total root biomass for Changling $(\mathrm{P}=$ 0.011), a marginally significant decrease of $31 \%$ for Hardware Ranch $(P=0.068)$, and a marginally significant increase of $92 \%$ for Richland $(\mathrm{P}=0.051$; data not shown). There also was 
a marginally significant increase in root biomass of $15 \%$ for Changling under rain-out shelters (P $=0.059)$.

Among sites, the log response ratios of the snow removal effects on aboveground biomass were significantly influenced by reduction in minimum soil temperature $(\mathrm{P}=0.028)$, and this effect was driven by the strong negative biomass responses of the five sites that experienced the largest decreases in minimum soil temperature (Fig. 5a). There was no significant relationship between the log response ratios of the aboveground biomass response to snow removal and the number of soil freeze-thaw cycles $(\mathrm{P}=0.91)$, minimum soil temperature $(\mathrm{P}=$ 0.32), January air temperature $(\mathrm{P}=0.30)$ or annual snowfall $(\mathrm{P}=0.27)$. The among site relationship between the log response ratios of the rain-out shelter effects on both aboveground biomass and reduction in minimum soil moisture was not significant $(\mathrm{P}=0.38$; Fig. $5 \mathrm{~b})$, and likewise, the log response ratios of the rain-out shelter effects were not significantly correlated with the percentage of precipitation blocked among sites $(\mathrm{P}=0.18)$. However, there was a marginally significant negative correlation among sites between the absolute magnitudes of the rain-out shelter effects on biomass and mean annual precipitation $(\mathrm{P}=0.07$; i.e. the driest sites in Fig. 4a featured the largest magnitude responses).

\section{Discussion}

Our results revealed that soil frost effects on plant biomass resulting from reduced snow cover indeed can be substantial relative to the effects of reduced spring and summer precipitation. These effects were most apparent for sites that experienced a meaningful reduction in minimum soil temperature in response to snow removal (in this case, $2{ }^{\circ} \mathrm{C}$ or greater 
at $2 \mathrm{~cm}$ soil depth). The severity of winter temperature on its own was not a reliable predictor of snow removal effects on aboveground biomass, in that there was no snow removal effect for Kernen, a relatively cold site, whereas snow removal affected biomass or cover for Lac du Bois and Golestan, respectively, which experience much milder winters in comparison (although Kernen experienced unusually low snow cover in the ambient plots during the study, which may have diminished its snow removal effect). Similarly, the total number of soil freeze-thaw cycles was not a reliable predictor of snow removal effects on aboveground biomass. The latter was not surprising given that the freeze-thaw cycles for many sites were of low amplitude (i.e. dropping only a degree or so below freezing), which often produces little damage (Henry, 2007); nevertheless, the number of freeze-thaw cycles can be influential when freezing is consistently more intense (Elliott and Henry, 2009), and the timing and duration of soil frost also can have important consequences for plant biomass responses (Malyshev and Henry, 2012). With respect to functional groups, legumes can be particularly susceptible to frost (Joseph and Henry, 2008), and declines in this functional group largely explained the snow removal effect at one site (ESW), but at other sites, declines in grass biomass and cover were responsible for the total biomass declines in response to snow removal.

While a substantial percentage of spring and summer precipitation (20 to $70 \%$, but typically $40 \%$ ) was blocked by the rain-out shelters, there were only significant reductions in aboveground biomass for three sites. As discussed previously, the effectiveness of rain-out shelters is contingent on the ambient weather over the course of study (Kreyling et al., 2017), and we anticipated minimal rain-out shelter effects may be observed in very dry or very wet years for a given site. For example, rain-out shelters should have no effect in the absence of rain, whereas a rain-out shelter plot may receive abundant rain in a very wet year; both scenarios 
might not be expected to produce large treatment effects on plant biomass. We did not observe a clear relationship between rain-out shelter effects on biomass and ambient growing season precipitation (relative to the climate normals), and one site (Kernen) that experienced extremely low rainfall exhibited a significant rain-out shelter effect. Likewise, the effect of the rain-out shelters on minimum soil moisture was a poor predictor of the aboveground biomass responses. However, it has been demonstrated previously that apart from total precipitation, the timing and size of individual rainfall events can play an important role in plant biomass responses (Fay et al., 2008; Kulmatiski and Beard, 2013). Moreover, the marginally significant negative correlation among sites between the absolute rain-out shelter effect size on biomass and mean annual precipitation indicated that biomass was generally the most responsive to rain-out shelter treatment in the driest sites, although the direction of the biomass response was not consistent. In addition to blocking rain, the rain-out shelter infrastructure blocks solar radiation and can affect plot temperature, but such infrastructure artifacts have been documented to be minimal (e.g. no detectable change in solar radiation for $30 \%$ rainfall interception, and $<10 \%$ decrease in solar radiation for 80\% rainfall interception; Yahdjian and Sala, 2002).

The drought treatment in our experiment was limited to one year, and greater effects on plant biomass can occur in response to multiple years of drought (Hoover et al., 2014). In addition, as addressed above, aboveground plant productivity appears to be more sensitive to increases in precipitation than to reductions (Wilcox et al., 2017), and while some northern regions are predicted to experience increased drought over the next century, others are predicted to experience increases in precipitation (IPCC, 2014). Therefore, better understanding of the interaction between increased summer and winter precipitation also remains an area of research 
needs in predicting plant climate change responses. Moreover, a better understanding of precipitation responses is also required for non-herbaceous systems.

One aspect of the plant responses to decreased precipitation that we were only able to document superficially was the root response. Over half of the sites collected root data, but this was limited to small-volume samples of standing biomass at a fixed depth, whereas changes in rooting depth and root turnover are often important facets of root responses to drought (Xu et al., 2015). The collection of the latter root data can be difficult to implement in a coordinated distributed experiment, given that such experiments are geared towards ease of sampling as a means of promoting widespread participation (Fraser et al., 2013). However, the collection of such data in the context of a coordinated distributed experiment would likely be of great value; despite the general finding that relative allocation of biomass to roots increases in response to severe drought, root responses to drought remain highly variable (Eziz et al., 2017). Furthermore, variability among experiments, particularly with respect to relative water availability, may be important in explaining the observed variation among studies (Poorter et al., 2012).

Interactions between frost and drought have been observed experimentally at the level of individual plants (Kreyling et al., 2012b; Kreyling et al., 2012c), and the secondary goal of our study was to explore frost-drought interactions at the plant community level. While none of these interactions were significant, there was only one site (Changling) where both significant frost and drought effects occurred. Given that the main effects of frost and drought were not significant for the remainder of the sites, it remains inconclusive based on our results whether frost-drought interactions may be important at the community level. Nevertheless, one insight gained from our study is that it may be unlikely for both of these stressors to coincide for a given site within the same year. There are of course facets of decreased winter precipitation other than 
increased soil frost (e.g. advanced spring phenology and decreased growing season soil moisture (Wipf et al., 2006; Iwata et al., 2010; Natali et al., 2012)) that could promote interactions between reduced winter and summer precipitation, but as described at the outset, in our study we specifically attempted to isolate the frost effect from these other effects.

\section{Conclusions}

Our study demonstrated that frost effects resulting from reduced winter precipitation are a potentially important component of the total annual effect of reduced precipitation on plant biomass, and these effects are not simply restricted to the coldest sites. Although our attempt to examine interactions between frost and drought was impeded by a lack of simultaneous frost and drought effects within sites, the result that many sites did not show significant responses to snow removal or rain-out shelters is in itself informative in the context of publication bias and metaanalysis; not only would the non-significant results in the current study have been difficult to publish on their own, but the coordinated distributed experiment encouraged participation by sites that otherwise would not have attempted snow removal or rain-out shelter experiments (e.g. snow manipulation experiments are typically not conducted at warmer sites). Moving forward, the broader inclusion of sites in coordinated field experiments can clearly impart greater generality and improved perspective in climate change research. 


\section{References}

Allen CD, Macalady AK, Chenchouni H, Bachelet D, McDowell N, Vennetier M, Kitzberger T, Rigling A, Breshears DD, Hogg EH, Gonzalez P, Fensham R, Zhang Z, Castro J, Demidova N, Lim JH, Allard G, Running SW, Semerci A, Cobb N. 2010. A global overview of drought and heat-induced tree mortality reveals emerging climate change risks for forests. Forest Ecology and Management 259: 660-684.

Blankinship JC, Hart SC. 2012. Consequences of manipulated snow cover on soil gaseous emission and $\mathrm{N}$ retention in the growing season: a meta-analysis. Ecosphere 3.

Bonham CD, Mergen DE, Montoya S. 2004. Plant cover estimation: a contiguous Daubenmire frame. Rangelands 26: 17-22.

Borer ET, Harpole WS, Adler PB, Lind EM, Orrock JL, Seabloom EW, Smith MD. 2014. Finding generality in ecology: a model for globally distributed experiments. Methods in Ecology and Evolution 5: 65-72.

Breshears DD, Cobb NS, Rich PM, Price KP, Allen CD, Balice RG, Romme WH, Kastens JH, Floyd ML, Belnap J, Anderson JJ, Myers OB, Meyer CW. 2005. Regional vegetation die-off in response to global-change-type drought. Proceedings of the National Academy of Sciences of the United States of America 102: 15144-15148.

Bruce TJA, Matthes MC, Napier JA, Pickett JA. 2007. Stressful "memories" of plants: Evidence and possible mechanisms. Plant Science 173: 603-608.

Campbell JL, Socci AM, Templer PH. 2014. Increased nitrogen leaching following soil freezing is due to decreased root uptake in a northern hardwood forest. Global Change Biology 20: 26632673.

Carlyle C, Fraser LH, Turkington R. 2014. Response of grassland biomass production to simulated climate change and clipping along an elevation gradient. Oecologia 174: 1065-1073.

Ciais P, Reichstein M, Viovy N, Granier A, Ogee J, Allard V, Aubinet M, Buchmann N, Bernhofer C, Carrara A, Chevallier F, De Noblet N, Friend AD, Friedlingstein P, Grunwald T, Heinesch B, Keronen P, Knohl A, Krinner G, Loustau D, Manca G, Matteucci G, Miglietta F, Ourcival JM, Papale D, Pilegaard K, Rambal S, Seufert G, Soussana JF, Sanz MJ, Schulze ED, Vesala T, Valentini R. 2005. Europe-wide reduction in primary productivity caused by the heat and drought in 2003. Nature 437: 529-533.

Comerford DP, Schaberg PG, Templer PH, Socci AM, Campbell JL, Wallin KF. 2013. Influence of experimental snow removal on root and canopy physiology of sugar maple trees in a northern hardwood forest. Oecologia 171: 261-269.

Dai AG. 2011. Drought under global warming: a review. Wiley Interdisciplinary ReviewsClimate Change 2: 45-65. 
Dai AG. 2013. Increasing drought under global warming in observations and models. Nature Climate Change 3: 52-58.

Daubenmire R. 1959. A Canopy-coverage method of vegetational analysis. Northwest Science 33: 43-64.

Dunne JA, Harte J, Taylor KJ. 2003. Subalpine meadow flowering phenology responses to climate change: Integrating experimental and gradient methods. Ecological Monographs 73: 6986.

Elliott AC, Henry HAL. 2009. Freeze-thaw cycle amplitude and freezing rate effects on extractable nitrogen in a temperate old field soil. Biology and Fertility of Soils 45: 469-476.

English NB, Weltzin JF, Fravolini A, Thomas L, Williams DG. 2005. The influence of soil texture and vegetation on soil moisture under rainout shelters in a semi-desert grassland. Journal of Arid Environments 63: 324-343.

Eziz A, Yan ZB, Tian D, Han WX, Tang ZY, ; Fang JY. 2017. Drought effect on plant biomass allocation: A meta-analysis. Ecology and Evolution 7: 11002-11010.Fay PA, Kaufman DM, Nippert JB, Carlisle JD, Harper CW. 2008. Changes in grassland ecosystem function due to extreme rainfall events: implications for responses to climate change. Global Change Biology 14: $1600-1608$.

Fraser LH, Henry HAL, Carlyle CN, White SR, Beierkuhnlein C, Cahill JF, Casper BB, Cleland E, Collins SL, Dukes JS, Knapp AK, Lind E, Long RJ, Luo YQ, Reich PB, Smith MD, Sternberg M, Turkington R. 2013. Coordinated distributed experiments: an emerging tool for testing global hypotheses in ecology and environmental science. Frontiers in Ecology and the Environment 11: 147-155.

Fraser LH, Jentsch A, Sternberg M. 2014. What drives plant species diversity? A global distributed test of the unimodal relationship between herbaceous species richness and plant biomass. Journal of Vegetation Science 25: 1160-1166.

Freppaz M, Celi L, Marchelli M, Zanini E. 2008. Snow removal and its influence on temperature and $\mathrm{N}$ dynamics in alpine soils (Vallee d'Aoste, northwest Italy). Journal of Plant Nutrition and Soil Science-Zeitschrift Fur Pflanzenernahrung Und Bodenkunde 171: 672-680.

Gaul D, Hertel D, Leuschner C. 2008. Effects of experimental soil frost on the fine-root system of mature Norway spruce. Journal of Plant Nutrition and Soil Science-Zeitschrift Fur Pflanzenernahrung Und Bodenkunde 171: 690-698.

Groffman PM, Driscoll CT, Fahey TJ, Hardy JP, Fitzhugh RD, Tierney GL. 2001. Colder soils in a warmer world: A snow manipulation study in a northern hardwood forest ecosystem. Biogeochemistry 56: 135-150. 
Harrison F. 2011. Getting started with meta-analysis. Methods in Ecology and Evolution 2: 1-10.

Henry GHR, Molau U. 1997. Tundra plants and climate change: the International Tundra Experiment (ITEX). Global Change Biology 3: 1-9.

Henry HAL. 2007. Soil freeze-thaw cycle experiments: Trends, methodological weaknesses and suggested improvements. Soil Biology \& Biochemistry 39: 977-986.

Henry HAL. 2008. Climate change and soil freezing dynamics: historical trends and projected changes. Climatic Change 87: 421-434.

Hillebrand H, Cardinale BJ. 2010. A critique for meta-analyses and the productivity-diversity relationship. Ecology 91: 2545-2549.

Hoover DL, Knapp AK, Smith MD. 2014. Resistance and resilience of a grassland ecosystem to climate extremes. Ecology 95: 2646-2656.

Huelber K, Gottfried M, Pauli H, Reiter K, Winkler M, Grabherr G. 2006. Phenological responses of snowbed species to snow removal dates in the Central Alps: Implications for climate warming. Arctic Antarctic and Alpine Research 38: 99-103.

IPCC, 2014: Climate Change 2014: Synthesis Report. Contribution of Working Groups I, II and III to the Fifth Assessment Report of the Intergovernmental Panel on Climate Change [Core Writing Team, R.K. Pachauri and L.A. Meyer (eds.)]. IPCC, Geneva, Switzerland, 151 pp.

Iwata Y, Hayashi M, Suzuki S, Hirota T, Hasegawa S. 2010. Effects of snow cover on soil freezing, water movement, and snowmelt infiltration: A paired plot experiment. Water Resources Research 46.

Joseph G, Henry HAL. 2008. Soil nitrogen leaching losses in response to freeze-thaw cycles and pulsed warming in a temperate old field. Soil Biology \& Biochemistry 40: 1947-1953.

Knapp AK, Avolio ML, Beier C, Carroll CJW, Collins SL, Dukes JS, Fraser LH, Griffin-Nolan RJ, Hoover DL, Jentsch A, Loik ME, Phillips RP, Post AK, Sala OE, Slette IJ, Yahdjian L, Smith MD. 2017. Pushing precipitation to the extremes in distributed experiments: recommendations for simulating wet and dry years. Global Change Biology 23: 1774-1782.

Kong RS, Henry HAL. 2016. Prior exposure to freezing stress enhances the survival and recovery of Poa pratensis exposed to severe drought. American Journal of Botany 103: 18901896.

Kreyling J, Haei M, Laudon H. 2012a. Absence of snow cover reduces understory plant cover and alters plant community composition in boreal forests. Oecologia 168: 577-587.

Kreyling J, Khan M, Sultana F, Babel W, Beierkuhnlein C, Foken T, Walter J, Jentsch A. 2017. Drought Effects in Climate Change Manipulation Experiments: Quantifying the Influence of Ambient Weather Conditions and Rain-out Shelter Artifacts. Ecosystems 20: 301-315. 
Kreyling J, Thiel D, Simmnacher K, Willner E, Jentsch A, Beierkuhnlein C. 2012b. Geographic origin and past climatic experience influence the response to late spring frost in four common grass species in central Europe. Ecography 35: 268-275.

Kreyling J, Wiesenberg GLB, Thiel D, Wohlfart C, Huber G, Walter J, Jentsch A, Konnert M, Beierkuhnlein C. 2012c. Cold hardiness of Pinus nigra Arnold as influenced by geographic origin, warming, and extreme summer drought. Environmental and Experimental Botany 78: 99108.

Kulmatiski A, Beard KH. 2013. Woody plant encroachment facilitated by increased precipitation intensity. Nature Climate Change 3: 833-837.

Malyshev AV, Henry HAL. 2012. N uptake and growth responses to sub-lethal freezing in the grass Poa pratensis L. Plant and Soil 360: 175-185.

Natali SM, Schuur EAG, Rubin RL. 2012. Increased plant productivity in Alaskan tundra as a result of experimental warming of soil and permafrost. Journal of Ecology 100: 488-498.

Poorter H, Niklas KJ, Reich PB, Oleksyn J, Poot P, Mommer L. 2012. Biomass allocation to leaves, stems and roots: meta-analyses of interspecific variation and environmental control. New Phytologist 193: 30-50.

Sheffield J, Wood EF. 2008. Projected changes in drought occurrence under future global warming from multi-model, multi-scenario, IPCC AR4 simulations. Climate Dynamics 31: 79105.

Skinner RH, Gustine DL, Sanderson MA. 2004. Growth, water relations, and nutritive value of pasture species mixtures under moisture stress. Crop Science 44: 1361-1369.

Svejcar T, Angell R, Miller R. 1999. Fixed location rain shelters for studying precipitation effects on rangelands. Journal of Arid Environments 42: 187-193.

Templer PH, Schiller AF, Fuller NW, Socci AM, Campbell JL, Drake JE, Kunz TH. 2012. Impact of a reduced winter snowpack on litter arthropod abundance and diversity in a northern hardwood forest ecosystem. Biology and Fertility of Soils 48: 413-424.

Tierney GL, Fahey TJ, Groffman PM, Hardy JP, Fitzhugh RD, Driscoll CT. 2001. Soil freezing alters fine root dynamics in a northern hardwood forest. Biogeochemistry 56: 175-190.

Trenberth KE, Dai AG, van der Schrier G, Jones PD, Barichivich J, Briffa KR, Sheffield J. 2014. Global warming and changes in drought. Nature Climate Change 4: 17-22.

Vankoughnett MR, Henry HAL. 2014. Soil freezing and N deposition: transient vs multi-year effects on plant productivity and relative species abundance. New Phytologist 202: 1277-1285. 
Venn SE, Morgan JW. 2007. Phytomass and phenology of three alpine snowpatch species across a natural snowmelt gradient. Australian Journal of Botany 55: 450-456.

Walter J, Jentsch A, Beierkuhnlein C, Kreyling J. 2013. Ecological stress memory and cross stress tolerance in plants in the face of climate extremes. Environmental and Experimental Botany 94: 3-8.

Whittaker RJ. 2010. Meta-analyses and mega-mistakes: calling time on meta-analysis of the species richness-productivity relationship. Ecology 91: 2522-2533.

Wilcox KR, Shi Z, Gherardi LA, Lemoine NP, Koerner SE, Hoover DL, Bork E, Byrne KM, Cahill J, Collins SL, Evans S, Gilgen AK, Holub P, Jiang L, Knapp AK, LeCain D, Liang J, Garcia-Palacios P, Penuelas J, Pockman WT, Smith MD, Sun S, White SR, Yahdjian L, Zhu K, Luo YQ. 2017. Asymmetric responses of primary productivity to precipitation extremes: A synthesis of grassland precipitation manipulation experiments. Global Change Biology 23: 43764385.

Wipf S, Rixen C, Mulder CPH. 2006. Advanced snowmelt causes shift towards positive neighbour interactions in a subarctic tundra community. Global Change Biology 12: 1496-1506.

Xu MH, Peng F, You QG, Guo J, Tian XF, Xue X, Liu M. 2015. Year-round warming and autumnal clipping lead to downward transport of root biomass, carbon and total nitrogen in soil of an alpine meadow. Environmental and Experimental Botany 109: 54-62.

Yahdjian L, Sala OE. 2002. A rainout shelter design for intercepting different amounts of rainfall. Oecologia 133: 95-101. 


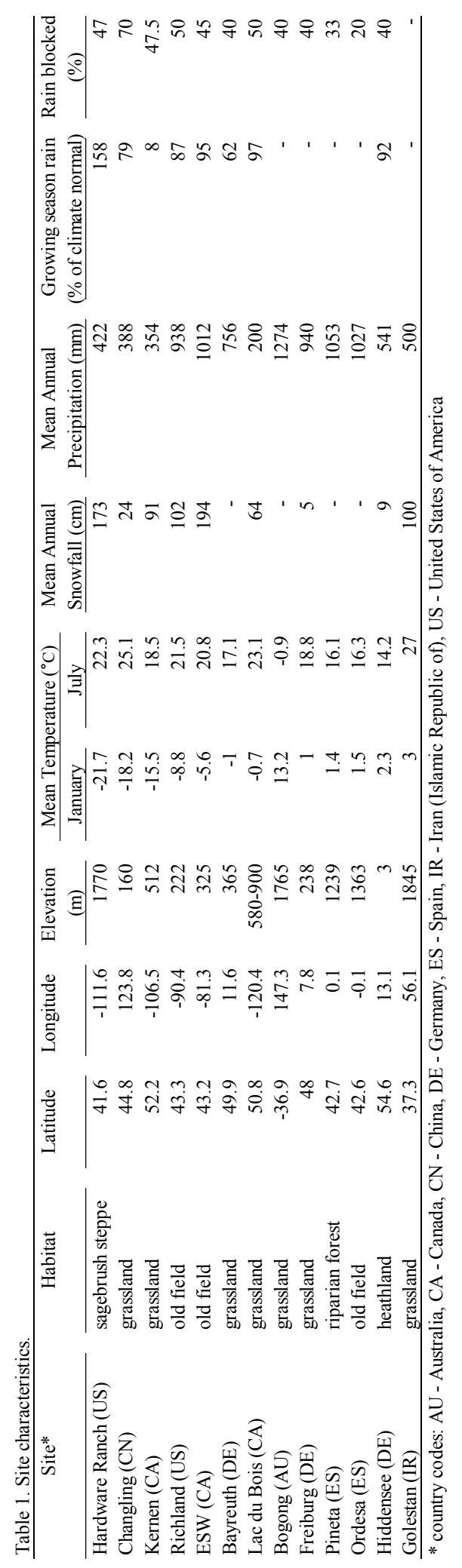


Table 2. Mean and standard error of minimum winter soil temperature and number of soil freeze-thaw cycles (ambient vs. snow removal plots) and minimum growign season soil moisture (ambient vs. rain-out shelter plots).

\begin{tabular}{|c|c|c|c|c|c|c|c|c|c|c|c|c|}
\hline \multirow{3}{*}{ Site } & \multicolumn{4}{|c|}{ Minimum soil temperature $\left({ }^{\circ} \mathrm{C}\right)$} & \multicolumn{4}{|c|}{ Number of freeze-thaw cycles } & \multicolumn{4}{|c|}{ Minimum soil moisture (\%) } \\
\hline & \multicolumn{2}{|c|}{ ambient snow } & \multicolumn{2}{|c|}{ snow removal } & \multicolumn{2}{|c|}{ ambient snow } & \multicolumn{2}{|c|}{ snow removal } & \multicolumn{2}{|c|}{ ambient rain } & \multicolumn{2}{|c|}{ rainout shelter } \\
\hline & mean & (s.e.) & mean & (s.e.) & mean & (s.e.) & mean & (s.e.) & mean & (s.e.) & mean & (s.e.) \\
\hline Hardware Ranch (US) & -5.4 & $(0.4)$ & -7.8 & $(0.3)$ & 40 & (6) & 45 & (9) & 8.4 & $(0.9)$ & 7.4 & $(0.2)$ \\
\hline Changling $(\mathrm{CN})$ & -12.1 & $(0.7)$ & -15.3 & $(0.2)$ & 14 & (2) & 15 & (2) & 8.7 & $(3.3)$ & 10.1 & $(3.1)$ \\
\hline Kernen (CA) & -12.1 & $(0.4)$ & -12.2 & $(0.4)$ & 16 & (4) & 10 & $(6)$ & 7.5 & $(2.1)$ & 5.4 & $(1.8)$ \\
\hline Richland (US) & -1.8 & $(0.2)$ & -6.6 & $(0.9)$ & 18 & (3) & 27 & (11) & 17.7 & $(1.8)$ & 16 & $(2.9)$ \\
\hline ESW (CA) & -3 & $(0.2)$ & -11.7 & $(0.8)$ & 32 & (7) & 24 & (2) & 17.7 & $(0.5)$ & 12.4 & $(0.8)$ \\
\hline Bayreuth (DE) & -2.2 & - & -2.3 & - & 21 & - & 10 & - & 16.8 & $(2.5)$ & 13.4 & $(1.2)$ \\
\hline Lac du Bois (CA) & -1.9 & $(0.2)$ & -5.5 & $(0.3)$ & - & - & - & - & 5.5 & (2.8) & 3.8 & $(4.2)$ \\
\hline Bogong (AU) & & - & - & - & - & - & - & - & - & - & - & - \\
\hline Freiburg (DE) & - & - & - & - & - & - & - & - & 7.6 & $(1.3)$ & 5.3 & $(1.7)$ \\
\hline Pineta (ES) & -1.9 & $(0.2)$ & -2.4 & $(0.2)$ & 20 & (4) & 52 & (5) & 38 & (1.8) & 38.2 & $(1.4)$ \\
\hline Ordesa (ES) & -2.9 & $(0.3)$ & -2.8 & $(0.2)$ & 27 & $(0)$ & 33 & (10) & 10.4 & $(0.7)$ & 10 & $(0.3)$ \\
\hline Hiddensee (DE) & -1.2 & $(0.3)$ & -0.9 & $(0.2)$ & 3.4 & $(0.6)$ & 2.5 & $(0.5)$ & 8.1 & $(0.7)$ & 7.1 & $(0.6)$ \\
\hline Golestan (IR) & -1.3 & $(0.8)$ & -3 & $(1.0)$ & 8 & (6) & 7 & (2) & - & - & - & - \\
\hline
\end{tabular}

Significant ANOVA treatment effects: minimum soil temperature - site $(\mathrm{P}<0.001)$, site $\times$ snow removal $(\mathrm{P}<0.001)$; number of freezethaw cycles - site $\times$ snow removal $(\mathrm{P}=0.002)$; minimum soil moisture - rainout shelter $(\mathrm{P}=0.041)$. 


\section{Figure captions:}

Fig. 1. Study site locations (black points). World map adapted from https://commons.wikimedia.org/wiki/Maps_of_the_world\#/media/File:BlankMap-Worldnoborders.png, Public Domain.

Fig. 2. Experimental design for a site with three rain-out shelters and three ambient rain plots. The snow removal subplots were nested randomly within the rain-out shelter and ambient rain plots.

Fig. 3. Mean a) aboveground biomass and b) total percent cover (i.e. total of all species cover values) for the ambient snow and snow removal sub-plots. Data pooled over the rain-out shelter treatments, and error bars denote standard error. Sites are ordered on the x- axis (left to right) from coldest to warmest mean January air temperature. Asterisks indicate significant differences $(\mathrm{P}<0.05)$ within sites, and crosses denote a marginally significant difference $(\mathrm{P}<0.1)$.

Fig. 4. Mean a) aboveground biomass and b) total percent cover (i.e. total of all species cover values) for the ambient rain and rain-out shelter plots. Data pooled over the snow removal treatments, and error bars denote standard error. Sites are ordered on the x- axis (left to right) from lowest to highest mean annual precipitation. Asterisks indicate significant differences $(\mathrm{P}<0.05)$ within sites, and crosses denote a marginally significant difference $(\mathrm{P}<0.1)$. 
Fig. 5. a) The snow removal effect on aboveground biomass (log response ratio) for each site as a function of the snow removal reduction of minimum soil temperature. b) The rain-out shelter effect on aboveground biomass (log response ratio) for each site as a function of the rain-out shelter reduction of minimum soil moisture. 
Fig. 1

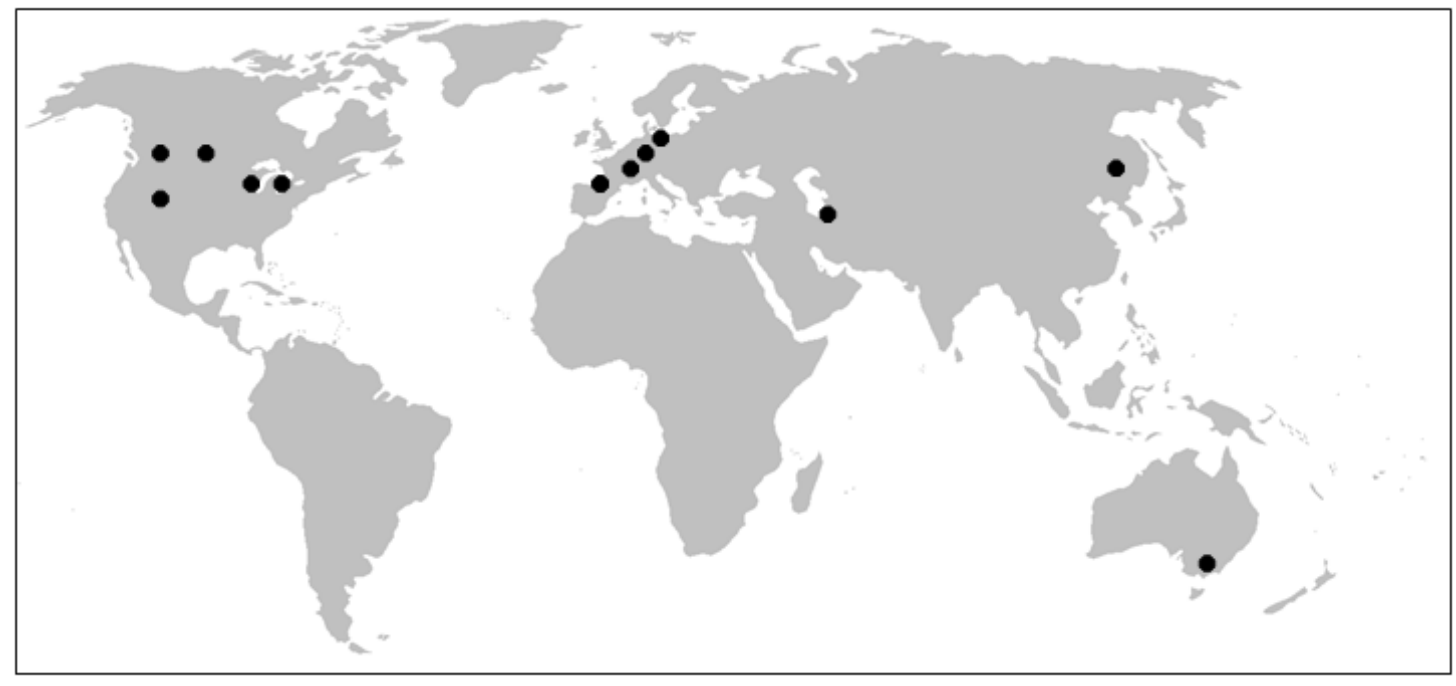


Fig. 2

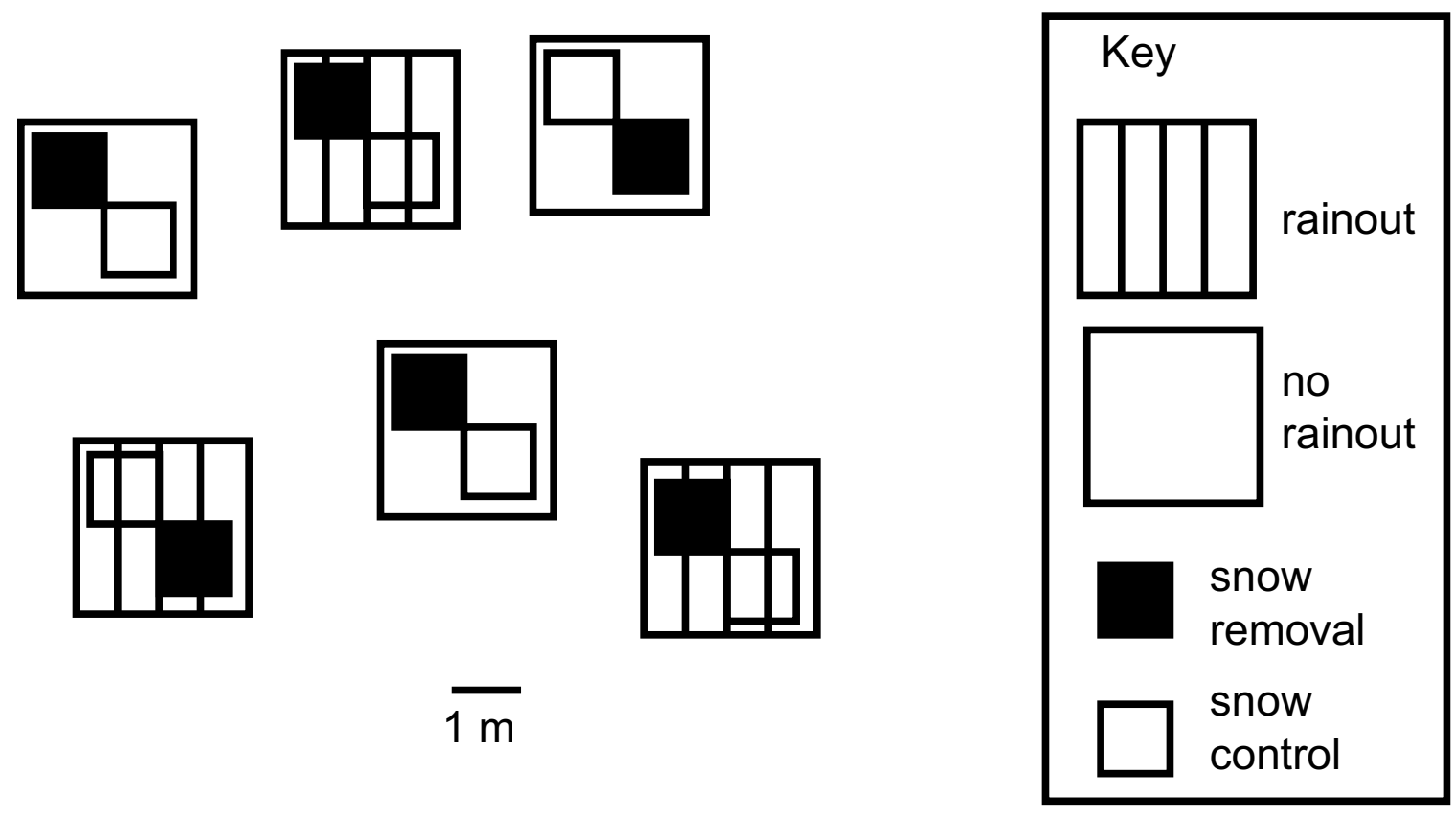


Fig. 3

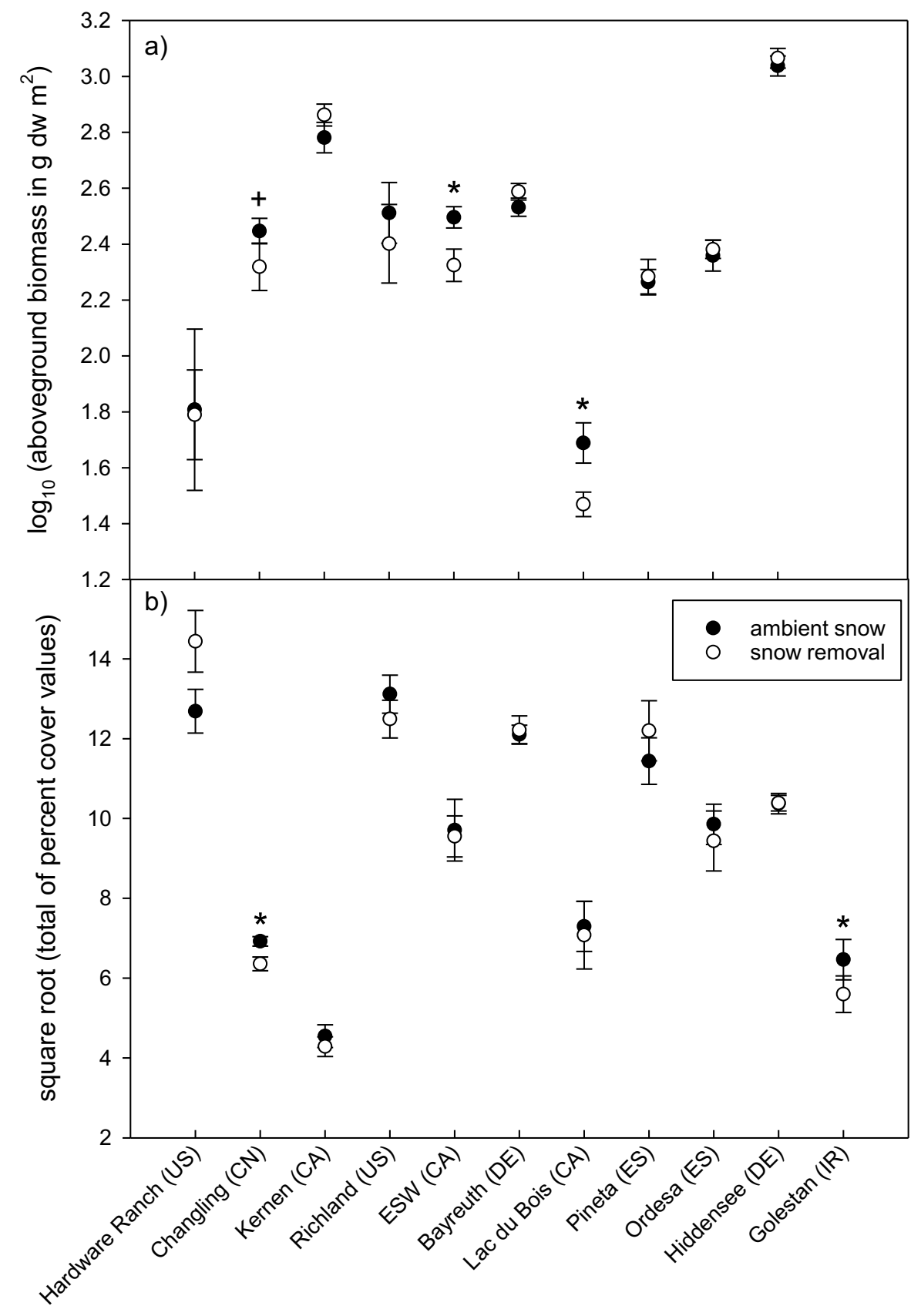


Fig. 4

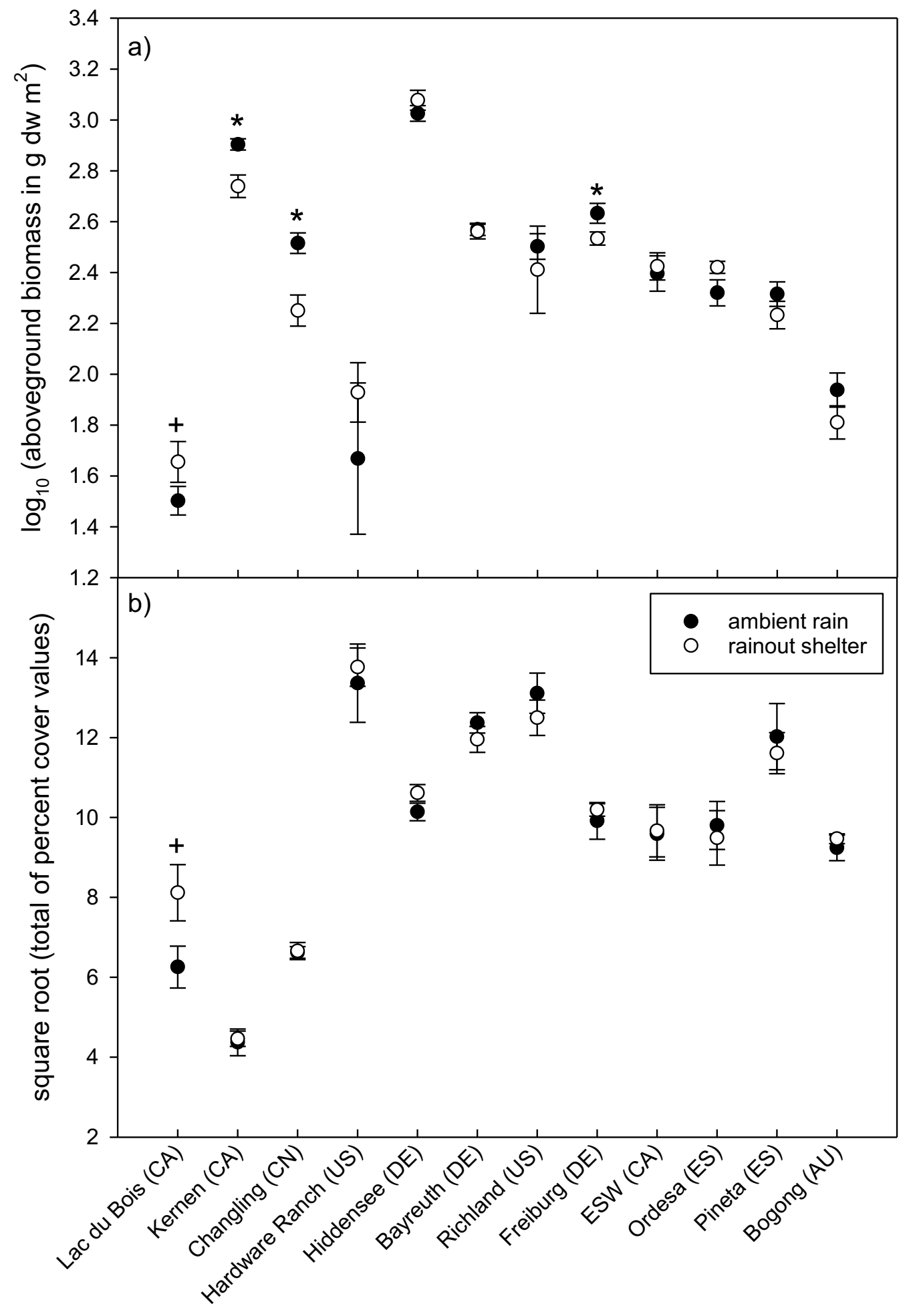


Fig. 5
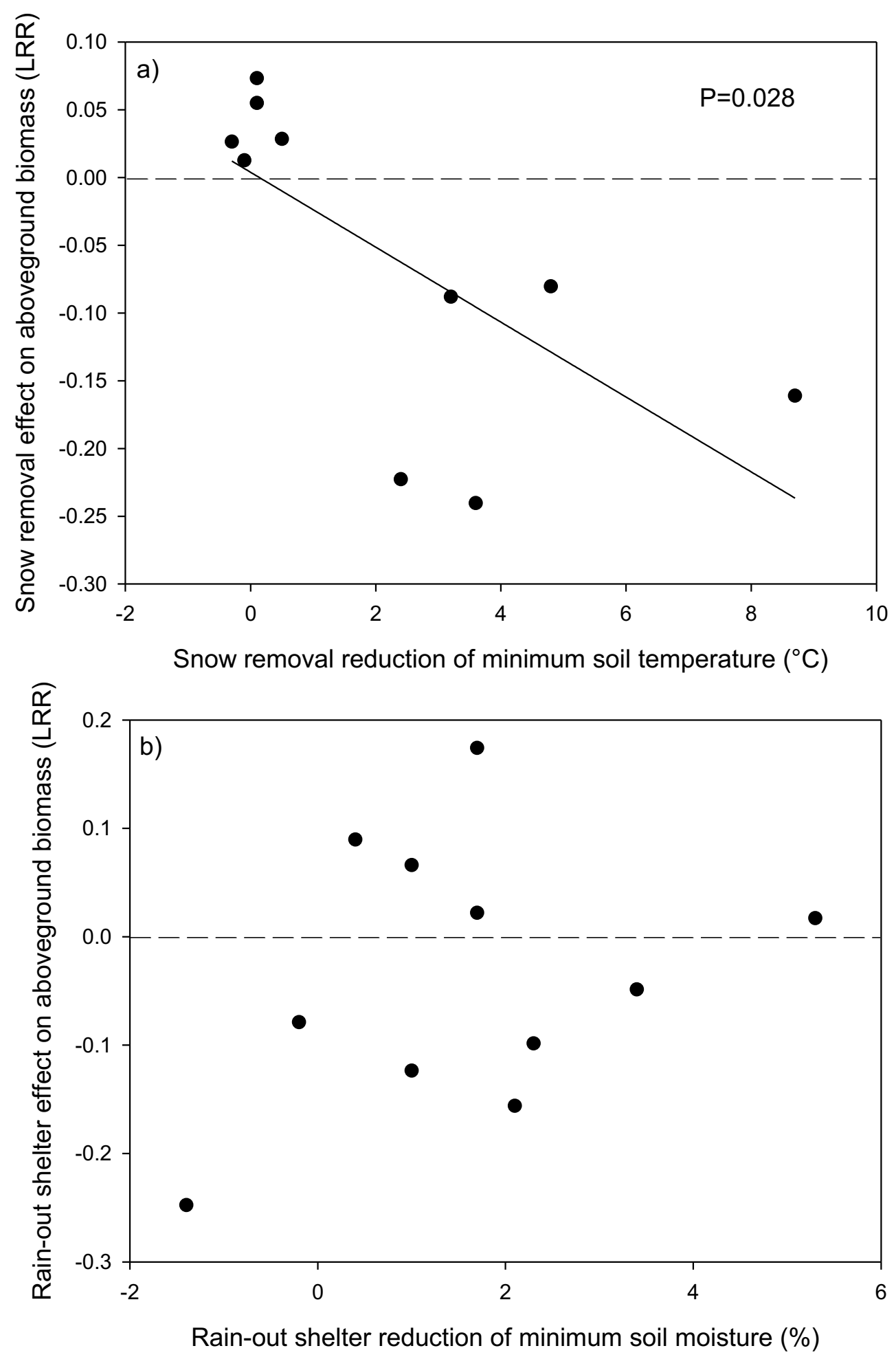